\title{
Mini-Review \\ Exercise training on cardiovascular diseases: Role of animal models in the elucidation of the mechanisms
}

\author{
Bruno Rodrigues \\ Daniele Jardim Feriani \\ Bruno Bavaresco Gambassi \\ Universidade Estadual de Campinas, Campinas, SP, Brasil \\ Maria Claudia Irigoyen \\ Instituto do Coração, São Paulo, SP, Brasil \\ Kátia De Angelis \\ Universidade Nove de Julho, São Paulo, SP, Brasil \\ Hélio José Coelho-Júnior \\ Universidade Estadual de Campinas, Campinas, SP, Brasil
}

\begin{abstract}
Cardiovascular diseases, which include hypertension, coronary artery disease/myocardial infarction and heart failure, are one of the major causes of disability and death worldwide On the other hand, physical exercise acts in the prevention and treatment of these conditions. In fact, several experiments performed in human beings have demonstrated the efficiency of physical exercise to alter clinical signals observed in these diseases, such as high blood pressure and exercise intolerance. However, even if human studies demonstrated the clinical efficiency of physical exercise, most extensive mechanisms responsible for this phenomenon still have to be elucidated. In this sense, studies using animal models seem to be a good option to demonstrate such mechanisms. Therefore, the aims of the present study are describing the main pathophysiological characteristics of the animal models used in the study of cardiovascular diseases, as well as the main mechanisms associated with the benefits of physical exercise.
\end{abstract}

Keywords: physical exercise; cardiovascular disease; experimental models.

\section{Introduction}

Cardiovascular disease (CVD) is the name of a larger construct, which involves diseases of the heart, brain vasculature and blood vessels ${ }^{1}$. Several data indicate that CVD is the major cause of disability and death worldwide ${ }^{1,2}$. To date, CVD seems to be responsible for $30 \%$ of the annual deaths in low and middle income countries ${ }^{2}$. Projections for the next years do not indicate a better scenario, since is expected that this number will increase exponentially ${ }^{2}$.

Among the variety of CVD risk factors, physical inactivity is highlighted as a phenomenon strongly associated with CVD development, regardless of body mass index ${ }^{2}$. The effects of physical activity (PA) (e.g., walking, climbing stairs) on CVD risk factors are widely known, which explains its popularity with healthy individuals who want to avoid $\mathrm{CVD}^{2}$. In turn, physical exercise (PE), which concerns planned and structured body movement aimed to improve one or more physical capacities, has been widely suggested as a powerful non-pharmacological tool by different international associations, in order to prevent and counteract the deleterious effects of CVD in the organic system, due its capacity to offer larger effects in comparison with $\mathrm{PA}^{2,3,4,5,6}$.

In fact, several studies, including systematic reviews and meta-analytic data, indicate that PE is capable of leading to changes in the pathophysiological course of different CVD, such as hypertension (HTN), coronary artery disease/myocardial infarction (MI) and heart failure (HF) ${ }^{7,8,9,10}$. Although the clinical effects of PE on the different CVD are already known, the mechanisms associated with such changes must still be elucidated.

It is widely acknowledged that experiments with humans have limited capacity to contribute to the investigation of the mechanisms associated with the effects of PE on CVD and, usually, inferences are limited to systemic analyses (i.e., plasma and/or serum).

In this sense, studies using animal models have emerged as an effective tool to explore the several mechanisms triggered by PE in different organs and tissues, as well as in the whole organic system. Regarding animal models in the CVD context, experiments have been performed with different types of animals, including species that spontaneously developed the disease due to genetic factors and animals that underwent surgical procedures.

In fact, HTN, for example, is commonly studied in Spontaneous Hypertensive Rats (SHR), since the pathogenesis of HTN in this species is multifactorial, as in humans. However, if necessary, researches can also study HTN triggered by specific alterations in the renal system (i.e., one kidney one clip [1K1C], two kidneys one clip [2K1C] and two kidneys two clip [2K2C]), using pharmacological approaches (i.e., L-NAME $\left[\mathrm{N}^{\omega}-\right.$ nitroL-arginine methyl ester], DOCA [deoxycorticosterone acetate]) and associated with diseases, such as obesity, and physiological conditions, such as menopause (i.e., ovariectomized), for 
example. Moreover, such possibilities are not exclusively related to HTN, and several possibilities are available in the context of MI (e.g., Left anterior descending coronary artery ligation [CAL], Ischemia-Reperfusion model [IRM] and MI-induced by isoproterenol) and HF (e.g., hyperadrenergic activity, CAL, doxorubicin, left coronary artery microembolization with polystyrene).

The mechanisms responsible for the beneficial effects of PE on CVD have been studied in some of the aforementioned models, and much has been discovered. To contribute with this Special Issue, denominated: Animal Studies: Contributions to Exercise Physiology, we aimed to provide a brief description of the mechanisms and clinical aspects observed in the animal models that are most used to study the effects of PE on CVD.

This knowledge is important not only for undergraduate students, but also for graduate and post-graduate students, as well as for researches that require an overview of the main animal models used in the context of PE and CVD.

\section{Hypertension}

HTN is one of the most prevalent diseases in adult life ${ }^{11}$. In older people, for example, the prevalence of HTN is elevated, reaching values above $60 \%$ in both sexes ${ }^{11,12}$. The main concern about this disease is its poor prognosis because patients with high blood pressure (BP) show increased risk for stroke (i.e., hemorrhagic and ischemic) and $\mathrm{MI}^{11,12}$. Moreover, a recent report from the World Health Organization (WHO) established HTN as the main risk factor for death worldwide ${ }^{11,12}$.

SHR have been widely used in scientific experiments, mainly because it is considered analogous with essential HTN in human by several authors ${ }^{13,14,15,16,17}$. This animal model of HTN was created by mating Wistar rats that showed the highest BP levels. After 20 generations, the animals began to develop spontaneous HTN in early adulthood ${ }^{13}$. In these animals, BP increases exponentially with aging, which occur mainly due to elevated vascular peripheral resistance (VPR) rather than to modified cardiac output $(C O)^{15,18}$.

As in humans, the pathogenesis of HTN in SHR seems to be multifactorial, since these animals show morphological and functional alterations on the different physiological elements that compose BP control, such as heart, kidney, blood vessels and autonomic control. Interestingly, these alterations have dissimilar time-courses, and factors associated with elevated BP in SHR are observed from the first weeks of life.

Data are inconclusive about HTN condition in young SHR (ySHR) ( $\sim 4$ weeks old), once during this age the animals present a high oscillation in BP values (as demonstrated by data using direct and indirect measurements) with some evidence indicating $\mathrm{HTN}^{19,20}$ — BP values next to $150 \mathrm{mmHg}$ - and others not $^{21,22}$. Therefore, during this time of life animals are generally denominated as pre-hypertensive. However, a significant number of evidence have been indicating that, even in the absence of alterations on BP measurements, morphological alterations on different vascular beds of the cardiovascular system and in the kidney, are observed in ySHR $21,22,23,24$.

In the kidney, for example, increased cross-sectional area (CSA) of the intima and adventitia layer, concomitantly with increased wall lumen, are found in the renal arteries of ySHR in comparison with age-matched normotensive control ${ }^{23}$. Data are also observed in other vascular beds (i.e., aorta, mesenteric), and evidence indicate elevated intima (IT), media (MT) wall thickness (WT), media-lumen ratio (M/L), media cross-sectional area

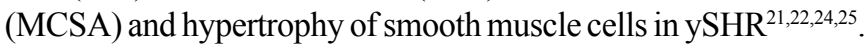
Such alterations increase linearly and progressively with aging, and results of modified vascular structure in 8-week and 12-week old SHR (adult SHR [aSHR]) are larger than in ySHR and agematched WKY control ${ }^{22}$. In this sense, results from analyses in the kidney of aSHR demonstrated increased indications of renal injury and abnormalities in comparison with normotensive animals ${ }^{26}$.

Nevertheless, experiments in the thoracic aorta of aSHR identified elevated mRNA expression of $\alpha$-actin (+9-fold), elastin (+6-fold) and collagen I and III (+11-fold) in comparison with normotensives27. Moreover, as observed in ySHR, the content of connective tissue, elastic fibers, and fibrils, as well as the CSA, were higher in the aorta of aSHR in comparison with age- matched control ${ }^{27}$.

Regarding functional alterations, aSHR show an endothelium phenotypic profile close to what is generally observed in endothelial dysfunction, characterized by increased reactive oxygen species (ROS) synthesis, oxidative stress activity and decreased antioxidant activity, culminating in a substantial impairment on endotheliumdependent dilation ${ }^{28,29,30}$. In fact, endothelium-dependent dilation is decreased in the vessels of aSHR in comparison with WKY ${ }^{28,29,30}$. Participation of the endothelium in this phenomenon seems to be clear when pre-treatment with L-Nitro-Arginine Methyl Ester (L-NAME) - a nitric oxide (NO) inhibitor - abolishes differences between normotensive and hypertensive animals ${ }^{30}$.

Noteworthy, NO is a molecule synthesized by the vascular endothelium is response to several stimuli (e.g., shear stress, acetylcholine $[\mathrm{ACh}]$ ) and it is the main action that occurs in the smooth muscle cells, causing vasodilation by altering calcium kinetics, through activation of soluble guanylate cyclase (sGC)/ cyclic guanosine monophosphate (cGMP) (sGC/cGMP) pathway ${ }^{31,32}$. Moreover, this free radical seems to be important to mediate the effects of other vasodilatory molecules, such as angiotensin (ANG) $(1-7)^{33,34}$. Interestingly, vasodilatory response to ANG (1-7) is decreased in the aorta of aSHR, and impairment on NO pathway activity is a possible hypothesis to explain this phenomenon ${ }^{29}$.

As aforementioned, increased oxidative stress activity is generally observed during endothelial dysfunction. In aSHR, this phenomenon is not observed only in the heart, lung and kidney - organs associated with cardiovascular control - but also in the aorta and erythrocytes ${ }^{35,36}$. On the other hand, superoxide dismutase (SOD), catalase (CAT) and glutathione peroxidase (GPx) - antioxidant enzymes that contribute to the control of oxidative stress - , as well as the total antioxidant activity, are found decreased ${ }^{35,36}$.

Oxidative stress decreases NO mainly due to anion superoxide (O2-) actions ${ }^{37,38,39,40,41}$. After superoxide anion (O2-) synthesis, by uncoupled endothelial NO synthase (eNOS), NAD(P)H oxidase and mitochondria, this molecule reacts quickly with NO, creating peroxynitrite (ONOO-) $)^{37,38,39,40,41}$, which, in turn, reacts with cellular elements that act in NO synthesis, such as tetrahydrobiopterin $(\mathrm{BH} 4)$, a precursor of $\mathrm{NO}^{37,38,40}$. Therefore, 
it is possible to observe that decrease in NO bioavailability is a retro-pathway, which, if not stopped, can cause serious damages to the homeostasis of the organic system, mainly on endothelial function.

One interesting issue about SHR animals concerns the association between autonomic control and vascular function. In the mesenteric vessels, for example, ySHR show higher sensitivity to noradrenaline (NA), demonstrated by early vasoconstrictor response, than WKY rats, which is associated with higher influx of calcium and lower baroreflex sensitivity (gain) $(\mathrm{BrS})^{22,42,43}$.

This phenomenon is exacerbated by age, since aSHR demonstrate not only higher sensibility to NA infusion and electrical stimulus, but also decreased vasodilator response after $\mathrm{ACh}$ infusion in mesenteric and carotid vessels ${ }^{22,23,43,44,45}$, as well as $\mathrm{BrS}$ in conscious and nonconscious rats ${ }^{47,48,49}$. Furthermore, evidence have been found that morphological and functional alterations on blood vessels, such as arterial stiffness, decreased endothelium-dependent dilation, and oxidative stress are associated with BrS impairment ${ }^{35}$. Thus, data indicate that vascular and morphological alterations in blood vessels are associated with cardiac autonomic control.

In this regard, aSHR showed increased cardiac and peripheral sympathetic activity ${ }^{19,26,44,47,48}$ and blocked of $\alpha_{1}$-receptor with prazosin inhibit in $\sim 95 \%$ of the vasoconstrictor response to electrical stimulation, causing absence of differences in relation to the response of control animals ${ }^{23}$. Several evidence have showed that aSHR presents reduced heart rate variability (HRV) and increased systolic AP variability (SAP), followed by alterations in analyses of the frequency domain, indicating alteration in the sympathovagal balance ${ }^{26}$. Moreover, this phenomenon is not just an effect of increased sympathetic activity discharge from the central nervous system to the periphery, but an environmental complex proving vasoconstrictor response.

This idea seems to be clear in the experiment of Reja et al. $(2002)^{49}$, who observed elevated $\alpha_{1 \mathrm{~A}}$-receptor $\left(\alpha_{1 \mathrm{~A}}-\mathrm{R}\right)$, concomitantly with decreased $\alpha_{2 \mathrm{~A}}$-receptor $\left(\alpha_{2 \mathrm{~A}}-\mathrm{R}\right)$, gene expression levels on neural system - central (i.e., ventromedial hypothalamus [VHM] and rostral ventrolateral medulla oblongata [RVLM]) and peripheral (i.e., spinal cord) - and on peripheral organs associated with BP control, as myocardium and adrenal medulla tissue studying aSHR ${ }^{50}$. Furthermore, this overexpression of $\alpha_{1 \mathrm{~A}}-\mathrm{R}$ on the central and peripheral nervous system and on the peripheral organs are positively correlated with $\mathrm{BP}$ in $\mathrm{SHR}^{49}$.

Yet, administration of phenoxybenzamine - a $\alpha$-adrenergic receptor blocker - causes significant decrease on BP and HR in a dose-dependent manner in comparison with normotensive control rats $^{50}$. High drug levels caused total absence of differences of the aforementioned parameters between aSHR and control groups ${ }^{50}$. Authors also tested the effects of $\beta$-adrenergic receptor blocker, propranolol, in cardiovascular parameters. Results indicate that inhibition of $\beta$-adrenergic receptor leads to significant decrease on HR in aSHR to levels similar to control group ${ }^{50}$.

Additionally to the morphological and functional alterations in the vascular endothelium, in organs associated with BP control (e.g., heart, kidney), and in the autonomic control of the cardiovascular system, an upregulation of some molecular pathways in the brain areas responsible for BP control are found in SHR.
As in the peripheral tissues, brain renin-angiotensin system (RAS) acts regulating cardiovascular control ${ }^{51,52}$. Importantly, during HTN the blood-brain barrier (BBB) is markedly disrupted in areas associated with autonomic cardiac control - such as RVLM, nucleus tractus solitarius (NTS) and paraventricular nucleus (PVN) - , which allows for extravasation of peripheral ANGII to these areas, as demonstrated trough infusion of fluorescently labeled ANGII in SHR ${ }^{117,118}$. Therefore, it is possible that elevated ANGII in the brain is, partially, explained by the peripheral activity of RAS ${ }^{117,118}$.

Regarding the pathway, in summary, after the cleavage of renin by the substrate angiotensinogen (Aogen), the decapeptide angiotensin I (ANG I) will be formed ${ }^{51,52}$. From the activity of the angiotensin-converting enzyme (ACE), ANG I is cleaved in an octapeptide, called angiotensin II (ANG II), which seems to be the neuropeptide responsible for RAS negative effects on cardiovascular control through its binding with $\mathrm{AT}_{1} \mathrm{R}^{51,52}$.

Seminal data demonstrated that inhibition of the activity of RAS components in the brain by direct ventricular infusion of saralasin — a ANGII antagonist — , or even by antisense treatment, with consequently impair $\mathrm{AT}_{1} \mathrm{R}$ and Aogen, leads to decrease on $B P$ values of aSHR in a dose-dependent manner ${ }^{16,53}$. Recent studies have confirmed these evidences, showing that the expression of RAS components, as ACE, $\mathrm{AT}_{1} \mathrm{R}$, Aogen, are increased in brain areas responsible for cardiovascular control (e.g., RVLM, NTS), which, in turn, is associated with BP values ${ }^{34,54}$.

Interestingly, BP modulation by RAS does not seem to occur alone, but in conjunction with the activity of ROS and inflammatory elements, such as proinflammatory cytokines, adhesion molecules, and transcription factors (nuclear factor- $\kappa \mathrm{B}[\mathrm{NF} \kappa \mathrm{B}])^{55}$. In fact, blockade of NFאB in the PVN leads to lowering of mean $\mathrm{BP}$, as well as decreased $\mathrm{mRNA}$ expression of proinflammatory cytokines, such as tumor necrosis factor- $\alpha(\mathrm{TNF}-\alpha)$, interleukin$1 \beta$ (IL-1 $\beta$ ) and IL-6 (IL-6), and ROS (e.g., $\left.\mathrm{O}_{2}^{-}, \mathrm{ONOO}^{-}\right)^{56}$. In addition, analysis of data from experiments on aSHR indicate that ROS and proinflammatory elements are elevated in similar brain areas, and times, supporting the idea of an integrated complex of cardiac control between these pathways in $\mathrm{SHR}^{34,47,48,54}$.

After elevation of ROS by RAS, $\mathrm{O}_{2}{ }^{-}$and other ROS can lead to phosphorylation of the extracellular signal-regulated kinases $1 / 2$ ( ERK 1/2), - a signaling protein kinase — which promptly activates NF $\kappa \mathrm{B}$ trough the inhibition of $\mathrm{I} \kappa \beta \alpha$, an inhibitory anchoring protein, allowing the translocation of NFKB to nucleus, increasing the synthesis of ROS and $\mathrm{PICs}^{39,47,57}$. In aSHR, mRNA expression of NAD(P)H oxidase and the activity of ROS are elevated in the PVN, followed by elevated phosphorylation of ERK $1 / 2$ and IKK $\beta$, in addition to $\mathrm{NF} \kappa \mathrm{B}$ binding to the DNA ${ }^{33,58}$. Moreover, data demonstrated that increased ROS, ERK $1 / 2$ and NF $\mathrm{NB}$ activity is associated with increased levels of PICs, as well as decreased levels of anti-inflammatory cytokines (i.e., interleukin-10 [IL-10]) in $\mathrm{aSHR}^{33}$. Considered together, these data indicate that, in the brain of aSHR, a molecular complex formed by RAS, ROS and PICs acts on cardiovascular control.

Regarding the mechanisms responsible for increased BP observed in aSHR, downstream of ROS and proinflammatory cytokine activity lead to alteration in autonomic cardiac 
control $^{59,60}$. In the experiment of Takagishi et al..$^{60}$, for example, exogenous IL-6 administrated by microinjection in the NTS causes $\sim 35 \%$ inhibition of baroreceptor bradycardia reflex gain in a dose-dependent manner ${ }^{60}$.

Moreover - despite the exacerbation of activity of hypertensive elements in the brain areas of SHR - some pathways, such as ANG 1-7/Mas receptor and anti-inflammatory cytokines (i.e., IL-10), that could act as counter-regulatory agents, consequently decreasing BP values, show lower expression in the brain of aSHR in comparison with normotensive age-matched control $^{33,34}$. ANG (1-7), for example, is formed by the cleavage of ANG II by ACE 2 and, in the brain areas of cardiovascular control, acts through Mas receptors in the tonic and reflex control of $\mathrm{BP}^{52,61}$. Yet, evidence indicates that ANG (1-7) control of BP can occur due to its influence on $\mathrm{BrS}^{52,61}$.

\section{The effects and mechanisms of PE on hypertension: evidences from $S H R$}

$\mathrm{PE}$ is considered a beneficial non-pharmacological therapy to induce decrease on BP values in hypertensive patients, being considered one of the most important changes in lifestyle of these patients $\mathrm{s}^{3,62}$. Several evidence indicate that aerobic PE is an effective stimulus to induce acute (hypotension post-exercise) and chronic decrease on BP values in humans ${ }^{3,63,64,65}$. Nevertheless, recent reviews (i.e., descriptive and meta-analyses) have described the potential of resistance training to contribute to this control ${ }^{58,66}$.

Experiments have demonstrated lower BP values in trained aSHR in comparison with sedentary aSHR after treadmill, swimming and resistance exercise $\mathrm{e}^{26,33,34,47,48,54,67}$. A recent metaanalysis, which analyzed 17 studies in SHR, confirmed these data and demonstrated that $\mathrm{PE}$ is capable of leading to significant decrease on BP values ${ }^{17}$.

Morphological and functional alterations on organs associated with BP control (e.g., heart, kidney) and on blood vessels are one of the most evident alterations triggered by PE in aSHR. In the aorta, for example, low to moderate aerobic physical training performed 5 days per week, one hour per day, over three months caused decrease on smooth cells volume, elastic components and connective tissue in the aorta ${ }^{27}$. These effects are followed by significant decrease in the mRNA expression of $\alpha$-actin, elastin, and collagen I and III ${ }^{27}$. Results were not different in the heart since collagen content and cardiac load were decreased, and myocardial performance index (MPI) and left ventricular chamber diameter were increased in aSHR submitted to moderate aerobic exercise during 10 weeks $^{68}$. Yet, swimming exercise decreased the number of sclerosis glomerular index in the kidney of $\mathrm{SHR}^{26}$.

Morphological alterations are generally followed by functional changes caused by oxidative stress and characterized by decreased endothelium-dependent dilation. PE seems to be an efficient stimulus to counter-regulate this phenotype. In fact, after PE, the total antioxidant activity was increased in the heart, kidney, aorta, and erythrocytes of aSHR ${ }^{35,36}$. Concomitantly, total oxidant activity was decreased in the lung, as well as lipid peroxidation (LPO) in the aorta ${ }^{35,36}$. Such alterations on pro and antioxidant molecules seem to be sensible, and after 10 weeks of detraining total oxidant activity is again increased in the kidney and in the liver ${ }^{36}$.

Functionally, PE improves ACh-mediated vasodilation and flow-mediated dilation in aSHR, restoring endothelial function in hypertensive animals ${ }^{28,30}$. PE also increases the vasodilator response to ANG (1-7) and improves the expression of Mas receptor in the aorta ${ }^{29}$. Interestingly, this response seems to be endothelium-dependent, since in endothelium-denuded vessels from trained SHR the vasodilator effect induced by ANG (1-7) was abolished. Moreover, NO and Mas receptor inhibition impairs the effects of $\mathrm{PE}^{29}$.

Improvements on autonomic cardiac control have been extensively studied and suggested as one of the main benefits in response to PE in hypertensive patients. In turn, use of SHR models have contributed to a better understanding of this phenomenon and Krieger et al. ${ }^{69}$ already indicated this change as one of the main physiological adaptations in response to PE.

As in humans, several evidence using different types of exercise (i.e., treadmill running, swimming) have indicated that PE is capable of improving HRV and SAPV, which is accompanied by improvement in sympathovagal balance in aSHR $26,47,48,68$. Furthermore, authors reported that the aforementioned changes are associated with total restore of $\mathrm{BrS}$ and vagal tonus, as well as sympathoinhibiton ${ }^{26,47,48}$. Regarding $\mathrm{BrS}$, the effects of $\mathrm{PE}$ have been cited since the late $1990 \mathrm{~s}^{69}$. In a seminal experiment, for example, Brum et al. ${ }^{70}$ observed that after 13 weeks of lowintensity aerobic PE the AP range for triggering baroreceptor activation and the relation between the baroreflex discharge and changes on SAP of aSHR were increased in comparison with sedentary animals ${ }^{70}$.

Interestingly, changes in cardiac and peripheral autonomic control after PE seem to occur through the afferent baroreceptor modulation68. In fact, experiments have indicated that aSHR submitted to sinoaortic denervation presented no alteration on BrS, HRV and SAP after PE protocol ${ }^{68}$.

Results from experiments on aSHR have contributed to understanding the effects of PE on the expression and activity of hypertensive elements in the brain areas responsible for cardiovascular control. Nevertheless, evidence were not limited to this specific issue, also demonstrating a possible correlation with cardiovascular function.

In fact, data demonstrate that low to moderate and moderate PE can cause significant decrease on RAS in the brain areas responsible for cardiovascular control of SHR. Data indicate lower mRNA expression of Aogen, ACE and AT1R in the NTS and RVLM of trained aSHR in comparison with sedentary $\mathrm{aSHR}^{34,54}$. On the other hand, ANG (1-7) pathway components (i.e., ACE2 and Mas receptor) showed elevated expression in the RVLM after exercise ${ }^{34}$. Similarly, ROS generation, NAD(P) $\mathrm{H}$ subunits (i.e., p4 $7^{\text {phox }}$ gp9 ${ }^{\text {phox }}$ ) activity, phosphorylated ERK $1 / 2$ and IKK $\beta$, NF $\kappa$ B translocation and proinflammatory cytokines synthesis (i.e., IL- 6 and TNF- $\alpha$ ) were lower in the PVN, RVLM of aSHR $33,34,47,48$. Noteworthy, such alterations on gene expression and activity seem to be correlated with cardiovascular control since decrease on RAS components and proinflammatory cytokines are correlated with improved $\mathrm{BrS}$ and AP decrease ${ }^{47,54}$. 
In an interesting experiment, Masson et al..$^{47}$ described the time-course changes in the expression of the aforementioned pathways in the PVN of aSHR ${ }^{47}$. During 8 weeks, animals were submitted to low-to-moderate intensity PE, which occurred 5 days per week, 1 hour per day. To evaluate the time-course, evaluations occurred before the start and during the $1^{\text {st }}, 2^{\text {nd }}$, $4^{\text {th }}$ and $8^{\text {th }}$ weeks of the PE program. Results showed that PE was capable of causing significant decrease on ROS, ERK1/2 phosphorylation, NF $\kappa \mathrm{B}$ translocation and proinflammatory cytokines synthesis in the first two weeks of exercise ${ }^{47}$. These results remained during the next weeks of training and were accompanied by an increase on autonomic cardiac control ${ }^{47}$.

In addition, experiments have demonstrated that $\mathrm{PE}$ can change the pattern of neurotransmitters release in PVN, as demonstrated by Jia et al. ${ }^{33}$, who submitted aSHR to 16 weeks of moderate-intensity aerobic exercise $(60 \%$ of maximal aerobic velocity, 5 days per week, 60 min per day). After exercise, authors observed lower levels of excitatory neurotransmitters - glutamate and NA - and high levels of inhibitory neurotransmitters - GABA - in the PVN of $\mathrm{SHR}^{33}$.

Table 1 shows a summary of the pathophysiological elements present in SHR, as well as the effects of PE.

Table 1. Physiopathological characteristics observed in SHR and the effects of PE

\begin{tabular}{lc}
\hline \multicolumn{1}{c}{ Physiopathological characteristics } & Effects of PE \\
\hline$\uparrow$ Blood pressure & $\downarrow$ \\
\hline \multicolumn{1}{c}{ Vascular } & \\
$\uparrow$ Adventitia CSA & $\downarrow$ \\
$\uparrow$ Media CSA & $\downarrow$ \\
$\uparrow$ Intima CSA & $\downarrow$ \\
Hypertrophy of smooth cells & $\downarrow$ \\
$\uparrow$ mRNA expression of genes associated with & $\downarrow$ \\
vascular remodelling & $\downarrow$ \\
\hline \multirow{2}{c}{ Endothelium } & $\uparrow$ \\
\hline$\uparrow$ ROS & $\downarrow$ \\
$\downarrow$ Antioxidant activity & $\downarrow$ \\
$\downarrow$ endothelium-dependent dilation & $\downarrow$ \\
\hline \multicolumn{1}{c}{ Cardiovascular autonomic control } & $\downarrow$ \\
\hline$\uparrow$ Cardiac sympathetic activity & $\downarrow$ \\
$\uparrow$ Perypheral sympathetic activity & $\downarrow$ \\
\hline Central Nervous System & $\downarrow$ \\
\hline PICs & $\downarrow$ \\
\hline
\end{tabular}

CSA: Cross-sectional area; PE: Physical exercise; PICs: Proinflammatory cytokines; SHR: Spontaneuos hypertensive rats; RAS: Renin-angiotensin system; ROS: Reactive oxygen species.

\section{Myocardial infarction}

As aforementioned, CVDs are the leading cause of mortality worldwide ${ }^{1}$. Among them, coronary artery disease (CAD) stands out due to its high risk of death ${ }^{11}$.

CAD has, as the main characteristic, the formation of atherosclerotic plaque in medium and large arteries. In summary, atherosclerotic plaque starts to build up due to endothelial dysfunction, which increases the permeability of the arterial intima layer to plasma lipoproteins — such as low-density lipoprotein (LDL), favoring the retention of such elements in the subendothelial space, when, later, in association with inflammatory markers (e.g., macrophages), the lipoproteins will undergo oxidation, forming the oxidized LDL (oxLDL) ${ }^{71}$. This phenomenon is followed by a myriad of inflammatory events, which have the formation of foam cells through phagocytosis of oxLDL by macrophages as the final event of the pathway ${ }^{71}$. It should be noted that the formation of oxLDL is associated with the quantum of available LDL in the plasma. Therefore, a higher number of LDL in the plasma will lead to increased formation of oxLDL and, consequently, of foam cells ${ }^{71}$.

Once developed, atherosclerotic plaque is composed of a cholesterol-rich lipid and a collagen-rich fibrous cap. The lipid content of the atherosclerotic plaque is the element responsible for its integrity, since disruption of this structure leads to formation of thrombus, which, if in contact with coronary circulation, can impair myocardial blood flow, thus causing ischemia and, possibly, $\mathrm{MI}^{71}$. Therefore, $\mathrm{MI}$ is defined as myocardial cell death due to prolonged ischemia ${ }^{72}$.

Studies using animal models are conducted to provide better understanding concerning the effects of PE pre and post MI. The most widely used protocol of MI in animals, mainly rodents, is occlusion of left anterior coronary artery. The MI surgery is conducted with the rat anesthetized with ketamine $(80 \mathrm{mg} / \mathrm{kg})$ and xylazine $(12 \mathrm{mg} / \mathrm{kg})$. After intubation, animals are positivepressure ventilated with room air at $2.5 \mathrm{~mL}, 65$ strokes/minute with a pressure-cycled rodent ventilator. To induce MI, a $2-\mathrm{cm}$ left lateral thoracotomy is performed in the third intercostal space, and the left anterior descending coronary artery is occluded with a nylon (6.0) suture at approximately $1 \mathrm{~mm}$ from its origin below the tip of the left atrium. It is important to mention that studies generally use a sham group, which is also submitted to the same procedures, except for myocardial ischemia, which was not induced in this case $\mathrm{e}^{73,74}$.

Following myocardial ischemia, it is possible to observe a substantial myocardial tissue loss, resulting in increased cardiac load that, in turn, induces ventricular remodeling of the infarcted border zone and the remote non-infarcted myocardium. Myocyte apoptosis, necrosis, and the resultant increased hemodynamic load activate multiple biochemical intracellular signaling that triggers left ventricular (LV) dilatation, hypertrophy, ventricular structure distortion, and collagen scar formations. Progression of MI observed in rats shows a similar pattern compared to that observed in human beings, since they have an altered survive rate and, after four weeks, present a phenotypic condition observed in $\mathrm{HF}^{75}$. 


\section{The effects and mechanisms of PE on MI: evidence from the surgical MI model}

$\mathrm{PE}$ is a non-pharmacological therapy widely recommended for CVD patients, which has been demonstrated to be effective in improving endothelial function ${ }^{76}, \mathrm{BrS}$, autonomic function ${ }^{77}$, as well as reducing tissue and systemic inflammatory state ${ }^{78}$.

Such improvements can be identified in human beings with tools already validated. Moreover, these evaluations are relatively easy and non-invasive if performed by an experienced evaluator, since, sometimes, just blood is necessary. However, in order to thoroughly evaluate the molecular, cellular and physiological mechanisms involved in these improvements, experimental models are necessary.

In fact, guidelines for rehabilitation programs in MI patients recommend that low-intensity PE starts approximately 1 month after $\mathrm{MI}^{5}$. However, animal studies have shown that if $\mathrm{PE}$ starts as soon as possible after MI this can further improve heart function, increasing maximum stroke volume, ejection fraction and attenuating the deterioration of LV contractility. These beneficial effects may be associated with PE-induced proliferation of cardiomyocytes, angiogenesis, attenuation of apoptosis in cardiomyocytes, due to improvement of myofilaments and management of intracellular calcium $\left(\mathrm{Ca}^{2+}\right)^{79}$.

It is known that - during and after MI - neurohumoral changes occur in order to minimize the consequences of reduced ventricular function and, consequently, cardiac output. On the other hand, chronically, autonomic imbalance is usually followed by abnormalities in cardiorespiratory reflex control, leading to impairment of $\mathrm{BrS}$ and function, and increased activation of ergoreflex and chemoreflex. In turn, evidence shows that $\mathrm{PE}$ allows for the improvement of autonomic function and subsequent reduction of mortality in humans ${ }^{77}$.

In this sense, in order to identify the mechanisms associated with improvement in autonomic function after PE in MI, Jorge et al. ${ }^{80}$ tested the effects of early aerobic exercise training on LV and autonomic function, hemodynamics, tissue blood flow, and mortality rate after MI in rats. Results from PE demonstrated that the intervention induced improvement of cardiac function (i.e., systolic and diastolic), followed by normalization of hemodynamic and regional blood flow, as well as improvement of autonomic control of peripheral circulation (i.e., $\mathrm{BrS}$ and increase on pulse interval $[\mathrm{PI}]$ ) and cardiac function. Furthermore, the authors observed increased SERCA2 and VEGF mRNA expression in LV. However, these benefits resulted in significant reduction in mortality rate in trained animals. According to the authors, the fact that early training restored autonomic control of circulation - represented by BrS and HRV - suggests that training may not only increase reflex responses mediated by the parasympathetic nervous system, but also suppress the influence of the sympathetic nervous system on ischemic heart disease. Moreover, elevated SERCA2 and VEGF mRNA expression suggests that these improvements are associated with alterations in intracellular calcium handling and blood supply.

Nerve growth factor (NGF) inducing cardiac sympathetic nerve sprouting is another characteristic observed post-MI. This phenomenon causes substantial sustained increase in sympathetic activity, resulting in downregulation and desensitization of $\beta 1$ and $\beta 2$-adrenergic receptor ( $\beta 1-\mathrm{AR}$ and $\beta 2-\mathrm{AR}$, respectively), and in upregulation of $\beta 3$-AR.

On the other hand, Chen et al. ${ }^{79}$, assuming that several evidences indicate that PE decreases sympathetic activity after MI, investigated whether such phenomenon occurred by inhibition of sympathetic nerve sprouting and restoring of $\beta 3-A R / \beta 1-A R$ ratio.

Results from the aforementioned study showed that PE inhibits cardiac sympathetic nerve sprouting and restores $\beta 3-\mathrm{AR} /$ $\beta 1$-AR balance after MI; which seems to occur due to increase in mRNA expression of $\beta 3$-AR. Moreover, authors observed increased activation of NO synthase 1 (NOS1) and NOS2 in the heart of animals submitted to $\mathrm{PE}$, indicating possible modulation of $\beta 3$-AR through NO pathway. Therefore, considered together, these results indicate that the protective effect of PE in MI can be modulated by $\beta 3-\mathrm{AR} / \mathrm{NO}$ pathway ${ }^{79}$.

In fact, it is known that after MI, $\beta 3-\mathrm{AR}$ is upregulated and activated due to high availability of NA. Dissimilar from the other $\beta$-receptor subunits, $\beta 3$ seems to play a protective role after $\mathrm{MI}$, acting as a counterregulatory mechanism during sympathetic overstimulation. Activation of $\beta 3-\mathrm{AR}$ induces NO production, which, in turn, is associated with NOS1 activity. NOS1 signaling leads to increased cardiac calcium cycling, followed by enhanced cardiac contraction and accelerated relaxation ${ }^{79}$.

Thus, the authors suggested that the beneficial effects of $\beta 3$-AR stimulation after PE are associated with the activation of NOS2 and NOS1, and the normalization of $\beta$-AR balance.

Regarding menopause, its main characteristic is the loss of the cardioprotective effects of estrogen, including on autonomic function. In this sense, Flores et al. ${ }^{81}$ investigated the effects of PE in MI-rats with ovarian hormone deprivation. Results demonstrated PE-induced improvement in cardiopulmonary $\mathrm{BrS}$, which was correlated with improvement in the autonomic control, represented by increased vagal tone in trained animals.

These data are confirmed by Rondon et al. ${ }^{82}$, who observed that the improvement in BrS induced by exercise training in infarcted rats is due, in part, to increased aortic depressor nerve activity, concomitantly with improving cardiac vagal modulation.

Studies have not been exclusively developed in order to verify the effects of $\mathrm{PE}$ after MI, but also its cardioprotective effects. In the experiment of Bozi et al. ${ }^{83}$ and Rodrigues et al. ${ }^{74}$, for example, the authors conducted a study in which rats performed aerobic exercise training for 8 weeks prior to MI surgery. After MI event, trained rats showed a smaller infarct extension and sympathetic activity, as well as increased $\mathrm{BrS}$, and parasympathetic modulation compared with sedentary infarcted animals. Additionally, Rodrigues et al. ${ }^{74}$ observed that improvements in autonomic balance and in parasympathetic modulation were strongly correlated with structural, systolic, diastolic and global LV function.

A recent study aimed to explore the effects of prior $\mathrm{PE}$ on the inflammatory aspects associated with MI. In fact, Santos et al. ${ }^{84}$ evaluated rats exercised prior MI and observed that exercise training modulated proinflammatory cytokines response triggered by MI. Furthermore, exercise group showed increased PPAR- $\alpha$. This molecule is a ligand-activated transcription factor that modulates the activity of genes involved in energy metabolism 
regulation and inflammatory processes, acting as a suppressor of the inflammatory state.

In the control group, negative correlation between TNF- $\alpha$ and NF- $\kappa \mathrm{B}$ was observed. However, these results were not observed in the trained group, which seems to be mediated by PPAR- $\alpha$ activation. Therefore, these data demonstrated that previously exercised animals had lower levels of local inflammatory markers and less myocardial apoptosis, which seemed to be related to the presence of PPAR- $\alpha$.

It is important to mention that due to significant functional loss in MI patients, mainly due to exacerbated muscle atrophy, resistance exercise was recommended as a complementary type of $\mathrm{PE}$ in relation to aerobic exercise. In this sense, Grans et al. ${ }^{116}$ evaluated the effects of dynamic resistance training on cardiac and hemodynamic function, as well as cardiovascular autonomic control after MI in rats. Results demonstrated that resistance exercise did not improve cardiac function. On the other hand, PE improved exercise tolerance and prevented additional loss in cardiovascular autonomic modulation.

Interestingly, Barboza et al. ${ }^{85}$ conducted one of the few studies that aimed to understand the effects of detraining on cardiac function, BrS, and mortality rate. To this end, MI rats were submitted to PE for 3 months with subsequent 1 month of detraining. The authors observed that $\mathrm{PE}$ reduced the infarcted area, concomitantly with improvement on systolic and diastolic functions, on BrS and reduction on mortality rate. Moreover, the detraining period was not enough to reverse the beneficial outcomes resulting from PE.

Table 2 presents a summary of the physiopathological elements present in MI rats, as well as the effects of PE.

Table 2. Physiopathological characteristics observed after MI in rats and the effects of PE

\begin{tabular}{lc}
\hline \multicolumn{1}{c}{ Physiopathological characteristics } & Effects of PE \\
\hline$\uparrow$ Akinetic LV area & $\downarrow$ \\
$\uparrow$ LV mass & $\downarrow$ \\
$\downarrow$ EF shortening & $\downarrow$ \\
\hline \multicolumn{2}{c}{ Cardiovascular autonomic control } \\
\hline$\downarrow$ BrS & $\uparrow$ \\
$\downarrow$ Cardiac sympathetic activity & $\uparrow$ \\
$\downarrow$ Cardiac parasympathetic activity & $\uparrow$ \\
\hline Cardiac calcium handling and Inflammation & $\downarrow$ \\
\hline$\downarrow$ SERCA2 & $\downarrow$ \\
$\uparrow$ PICs & $\uparrow$ \\
\hline \multirow{2}{c}{ Outcomes } & $\downarrow$ \\
\hline Exercise tolerance & \\
\hline Mortality rate & \\
\hline
\end{tabular}

BrS: Baroreflex sensitivity; EF: Ejection fraction; LV: Left ventricular; PE: Physical exercise; SERCA2: sarcoplasmic reticulum Ca2+-ATPase; PICs: Proinflammatory cytokines.

\section{Heart Failure}

Heart failure (HF) is a complex clinical condition that occurs in response to ventricular dysfunction due to structural and functional alterations in the heart, which lead to decreased capacity of the heart to pump blood to itself and to the periphery ${ }^{5,6,86}$. To counteract such alterations, in an attempt to regulate $\mathrm{CO}$, neurohumoral compensatory mechanisms (e.g., the sympathetic nervous system [SNS]) are increased during $\mathrm{HF}^{87}$. Although, initially, this phenomenon seems advantageous, chronic activation of the SNS has a toxic effect on the organic system of HF patients ${ }^{87}$.

In this sense, in order to study the relation between hyperadrenergic activity and $\mathrm{HF}, \alpha_{2 \mathrm{~A}} / \alpha_{2 \mathrm{C}}$ adrenergic receptor (AR) knockout $(\mathrm{KO})$ mice was developed by mating two heterozygous C57B16 mice: a $\alpha_{2 \mathrm{~A}}$-ARKO and a $\alpha_{2 \mathrm{c}}$-ARKO ${ }^{88}$. During the first months of life ( $1^{\text {st }}$ to $4^{\text {th }}$ month), these animals present no evident signals of HF, although muscular and cardiac abnormalities may be observed in this period ${ }^{88}$.

In fact, exercise intolerance, pulmonary edema associated with ventricular dysfunction (e.g., lower fractional shortening), and cardiac remodeling (e.g., cardiac hypertrophy) are significantly highlighted from the $5^{\text {th }}$ month of life ${ }^{89,90,91}$. The development of HF reaches the peak during the $7^{\text {th }}$ month when it is proposed that these animals developed a severe HF phenotype ${ }^{91,92,93}$. In addition to the high mortality rate found in $\alpha_{2 \mathrm{~A}} / \alpha_{2 \mathrm{Ca}} \mathrm{ARKO}$ mice, the animals present rest tachycardia and increased plasma NA levels due to increased adrenergic activity ${ }^{92,93,94,95 .}$

Cardinal manifestations in HF patients involve limited muscular and cardiac functioning, leading the patient to poor prognosis ${ }^{6}$. Regarding muscular functioning, skeletal myopathy consists of intrinsic alterations in skeletal muscle observed during $\mathrm{HF}$, which are indicated to be responsible for exercise intolerance and early fatigue $^{96,97}$. This condition is one of the main features present in cardiac cachexia syndrome and is strongly associated with poor outcomes ${ }^{96}$. In addition to the alterations in skeletal muscle structure and function, skeletal myopathy is associated with a shift toward fast twitch fibers, oxidative stress, local and systemic inflammatory state (i.e., elevated TNF- $\alpha$ ), and muscle metabolic dysfunction (i.e., mitochondrial respiration, energy transfer system and $\mathrm{pH}$ regulation) in response to stress ${ }^{93,96,98,99,100,101}$.

This phenotype is not well established in 3-month old $\alpha_{2 \mathrm{~A}} / \alpha_{2 \mathrm{Ca}}$ ARKO mice ${ }^{90,92,102}$. However, from the $5^{\text {th }}$ month of life, these animals present suggestible muscle profile of skeletal myopathy due to decreased motor performance (i.e., Rotard test), increased oxidative stress (i.e., lipid hydroperoxidation and protein carbonylation), gastrocnemius capillary rarefaction, muscle atrophy of type I and type II fibers and, due to all these factors, exercise intolerance $\mathrm{e}^{8,91,93,95,101,102}$.

Catabolic (i.e., ubiquitin-proteasome system [UPS]) and anabolic muscle pathways (i.e., insulin growth factor-1 [IGF-1]) are not exclusively associate with muscle mass homeostasis during aging and stroke ${ }^{57}$, to name a few, but also seem to be present in skeletal myopathy of $\mathrm{HF}^{93,101}$. Observations in $\alpha_{2 \mathrm{~A}} / \alpha_{2 \mathrm{Ca}} \mathrm{ARKO}$ mice with established congestive HF (i.e., 7 months of age) showed that these animals present decreased IGF-1 protein content, and phosphorylated $\mathrm{AKT}^{\mathrm{Ser} 473}, 4 \mathrm{E}-\mathrm{BP} 1^{\mathrm{Thr} 37 / 46}, \mathrm{p} 70 \mathrm{~S} 6 \mathrm{~K}^{\mathrm{Thr} 389}$ and GSK3 $3 \beta^{\mathrm{Ser} 9}$ protein content, as well as increased $26 \mathrm{~S}$ proteasome activity, in 
soleus muscle ${ }^{93}$. Moreover, evidences allow to infer that catabolic pathways are activate by oxidative stress and inflammatory state $^{99,101}$. Besides muscular functioning disorders, several levels of alterations - functional and structural — are observed in the heart of HF patients. In relation to cardiac function, is knowledge that $\mathrm{HF}$ associated with hyperadrenergic activity is followed by calcium $\left(\mathrm{Ca}^{2+}\right)$ cardiac kinetics impairment.

It is important to mention that $\mathrm{Ca}^{2+}$ has a crucial role in cardiac excitation-contraction coupling (ECC), since this molecule regulates muscle contraction acting as a critical intermediary between the electrical stimulus and the coupling of actin. Here, it is described an overview of this phenomenon, while more detailed and extensive reviews were performed by several authors ${ }^{103,104,105}$.

Initially, to generate cardiac systole, the action potential propagates trough the membrane of the cardiomyocyte leading to its depolarization (from $\sim-90 \mathrm{mV}$ to $\sim+20 \mathrm{mV}$ ) and, consequently, opening of the voltage-gated sodium $\left(\mathrm{Na}^{+}\right)$channels, mainly $\mathrm{Na}_{\mathrm{y}} 1.5$, allowing $\mathrm{Na}^{+}$influx ${ }^{103,105}$. The crescent increase on ion $\mathrm{Na}^{+}$concentration alters the membrane voltage, until reaching the threshold to the opening of the L-type voltagegated $\mathrm{Ca}^{2+}$ channels - in this case, $\mathrm{Ca}_{\mathrm{v}} 1.2^{105}$. Subsequent to the increase in cytosolic $\mathrm{Ca}^{2+}$ bioavailability ( $\sim 10$-fold $)$, the ryanodine receptors 2 (RyR2) - the predominant subtype of RyR in the cardiac sarcoplasmic reticulum (SR) - are activated by a $\mathrm{Ca}^{2+}$-dependent mechanism, leading to $\mathrm{Ca}^{2+}$ release in the junctional zone - a space between cardiac sarcollema and SR -, which, subsequently, migrates to the cytosol, binding in its site on the troponin $\mathrm{C}$, allowing for muscle contraction through actin-myosin interaction ${ }^{103,104,105}$. During cardiac diastole, a decrease in $\mathrm{Ca}^{2+}$ bioavailability is necessary to cause cardiac muscle relaxation ${ }^{104,105}$. This process is dependent on proteins involved in transsarcolemmal flux and sarcoplasmic reuptake of $\mathrm{Ca}^{2+103,105}$. Regarding transsarcolemmal flux, $\mathrm{Na}^{+} / \mathrm{Ca}^{2}$ exchanger (NCX) is one of the main cellular mechanisms responsible for the clearance of $\mathrm{Ca}^{2+}$ in the cardiomyocyte ${ }^{103}$. NCX is located in the cardiac cell membrane and - through the electrochemical gradient - exchanges one $\mathrm{Ca}_{2}{ }^{+}$ion to the extracellular milieu at the same time that uptakes three $\mathrm{Na}^{+}$ions ${ }^{103,105}$. The sarco/ endoplasmic reticulum $\mathrm{Ca}^{2+}$-ATPase protein $2 \mathrm{a}$, henceforth denominated as SERCA2a, is another important cardiac structure with key role in calcium handling ${ }^{103}$. During cardiac systole, SERCA2a remains inhibited by dephosphorylated phospholamban (PLN) ${ }^{103,105}$. However, after its phosphorylation by PKA and $\mathrm{Ca}^{2+}$ /calmodulin-dependent protein kinase (CaMKII), PLN allows SERCA to sequester $\mathrm{Ca}^{+}$from cytosol, contributing to cardiac relaxation ${ }^{103,104,105}$. It is important to mention that other structures, such as plasma membrane $\mathrm{Ca}^{2+}$ ATPase (PMCA) and the mitochondrial uniporter seem to contribute, in a lower magnitude, to $\mathrm{Ca}^{2+}$ clearance during cardiac diastole ${ }^{103}$.

The failing heart is characterized by marked contractile (i.e., systolic and diastolic) dysfunction and high prevalence of arrhythmias, which has been considered, at least in part, as a result of decreased SR $\mathrm{Ca}^{2+}$ handling ${ }^{104,105,106}$. In fact, in vitro experiments with human HF cardiac cells demonstrated smaller amplitude of $\mathrm{Ca}^{2+}$ transient, followed by lower $\mathrm{SR} \mathrm{Ca}^{2+}$ content and load, as well as slow decline of $\mathrm{Ca}^{2+}$ during action potential depolarizing in comparison with healthy hearts ${ }^{107}$.
Moreover, detailed analysis adds data to the aforementioned and mentions several other alterations on cardiac $\mathrm{Ca}^{2+}$ transient, such as decreased $\mathrm{Ca}^{2+}$ sequestration during cardiac diastole, decreased SR $\mathrm{Ca}^{2+}$ stores during cardiac systole, elevated $\mathrm{Ca}^{2+}$ availability during cardiac diastole and elevated $\mathrm{SR} \mathrm{Ca}^{2+}$ leak - which is the inappropriate $\mathrm{Ca}^{2+}$ release during diastole ${ }^{104,105}$. Interestingly, authors have suggested the key role of SERCA2a and RyR2 in this phenotype ${ }^{104,105}$.

Regarding cardiac SERCA2a, experiments have demonstrated a decrease of $57 \%$ on its activity in HF hearts ${ }^{107}$. This phenomenon seems to be strongly associated with decreased cardiac $\mathrm{Ca}^{2+}$ uptake during diastole, concomitantly with increased inhibition on $\mathrm{PLN}^{104}$. In turn, in the experiment of AI et al. ${ }^{106}$, the authors observed decreased RyR 2 mRNA and protein expression in the LV of HF rabbits ${ }^{106}$. However, during chronic hyperadrenergic state, which is present in HF, activation of cardiac $\beta$-receptors leads to decrease on calstabin 2 and increase on PKA phosphorylation at Ser 2808 causing "leaky" of RyR2 and, consequently, diastolic SR $\mathrm{Ca}^{2+}$ leak $^{104}$.

SERCA2a, NCX and SERCA2a/NCX are decreased by $26 \%$ and $34 \%$, respectively, in the heart of $\alpha_{2 \mathrm{~A}} / \alpha_{2 \mathrm{Ca}} \mathrm{ARKO}$ mice ${ }^{92,94}$. Concomitantly, it is possible to observe increase on $\mathrm{NCX}^{94}$. In relation to RyR2, its expression is not changed in $\alpha_{2 \mathrm{~A}} / \alpha_{2 \mathrm{Ca}} \mathrm{ARKO}$ mice ${ }^{92}$.

Due to several compensatory stimuli, including hyperadrenergic activity, HF patients may present cardiac remodeling, which involves the combination of several mechanisms. Cardiac hypertrophy is the major pathophysiological response to stress in HF. Initially, the hypertrophic response is beneficial, since it minimizes parietal stress and maintains contractile performance. However, over time, this response becomes harmful, aggravating HF. Nevertheless, such response is usually related to detrimental changes in the components of extracellular matrix, reduced myocardial vascularization, and fibrosis ${ }^{87,108,109}$.

Cardiac fibrosis is caused by excessive accumulation of collagen in the heart during pathological remodeling. As a result of fibrosis, electrical conduction is impaired and the risk of arrhythmias is increased ${ }^{110,111}$. The development of fibrosis alters the normal operation of the extracellular matrix and may lead to systolic and diastolic dysfunctions. The fibrotic tissue also contains myofibroblasts with contractile properties, participating in the collagen regulation. In response to paracrine and autocrine components, such as circulating hormones, mechanic stress, and proinflammatory cytokines, and segregation of fibrillar collagen precursors, as well as signaling molecules responsible for the interaction between parenchymal cells and extracellular matrix ${ }^{111}$.

Another mechanism involved in cardiac remodeling is oxidative stress, which may impair the contractile function - through changes in the proteins that participate in the excitation-contraction coupling - and activate signaling kinases hypertrophy, activate matrix metalloproteinases, and trigger apoptosis ${ }^{112}$. In this sense, cardiomyocyte apoptosis mechanism has been considered fundamental in the progress of HF. The apoptotic rate occurring in HF is small; however, this phenomenon has a larger influence on myocardial structure and function. Apoptosis begins by activation of caspases (cysteinyl-aspartate-directed proteases), which cleave vital substrates causing cell death. 
Caspase substrates in the heart comprise, for example, troponin, tropomyosin, $\alpha$-actin, and myosin chains ${ }^{113}$.

Apoptosis may occur by the extrinsic or intrinsic pathways. Briefly, in the extrinsic pathway, a death binder (such as FasL or TNF- $\alpha$ ) activates a death receptor, triggering the death-inducing signaling complex, activating caspase-8, which, in turn, activates caspase-3, causing apoptosis. In the intrinsic pathway, mitochondria are essential to mediate the apoptotic process. The mitochondria release cytochrome $\mathrm{c}$ into the cytosol, causing the formation of an activation complex — the apoptosome containing apoptotic protein activating factor-1 and caspase-9, leading to activation of other caspases, such as caspase- $3{ }^{114}$.

In 5-7-month old $\alpha_{2 \mathrm{~A}} / \alpha_{2 \mathrm{Ca}}$ ARKO mice, it is possible to observe increased heart height, LV mass, cardiomyocyte width and CSA, as well as cardiac fibrosis and collagen volume, suggesting a phenotype generally observed in remodeled hearths ${ }^{89,91,94,95,102}$. In the study of Pereira et al..$^{90}$, quantitative morphometric analyses indicated that cardiomyocyte width and cardiac collagen were, respectively, $28 \%$ and $55 \%$ increased in $\alpha_{2 \mathrm{~A}} / \alpha_{2 \mathrm{Ca}}$ ARKO mice in comparison with age-matched control ${ }^{90}$.

Nevertheless, the failing heart of $\alpha_{2 \mathrm{~A}} / \alpha_{2 \mathrm{Ca}} \mathrm{ARKO}$ mice show, associated with structural alterations, decreased fractional shortening (FS) and increased LV dilation linked to increased left ventricular end-systolic dimension (LVSED) and left ventricular end-diastolic dimension (LVEDD), characterizing LV dysfunction phenotype ${ }^{89,94,95,102}$.

\section{The effects and mechanisms of PE on HF: evidence from $\alpha_{2 A} / \alpha_{2 C} A R K O$}

Physical inactivity contributes to the progression of HF, whereas PE has been widely recommended as a non-pharmacological therapy capable of counteracting the deleterious effects of $\mathrm{HF}$ on the organic system ${ }^{4,97,109}$.

Evidence have demonstrate the effectiveness of moderate intensity PE (i.e., $60 \%$ of the maximal workload, 1 hour per day, 5 days per week, for 8 weeks) to increase exercise tolerance in $\alpha_{2 \mathrm{~A}} / \alpha_{2 \mathrm{Ca}}$ ARKO mice to levels similar to those observed in agematched WT ${ }^{90,93,94,95,96,97,101}$. Of interest, PE does not seem to act just by reversing the deleterious effects of HF in muscle functioning in the established pathology, but evidence has indicated its action in preventing the development of such effects ${ }^{92,102}$.

In fact, in the experiments of Medeiros et al. ${ }^{92,115}$, lowto-moderate swimming trained 3-month old $\alpha_{2 \mathrm{~A}} / \alpha_{2 \mathrm{Ca}} \mathrm{ARKO}$ mice ( 5 days per week, 60 minutes per day, during 8 weeks) presented preserved exercise tolerance during the development of $\mathrm{HF}$, in comparison with age-matched control ${ }^{92,111}$. Moreover, it is important to mention that inhibition of the development of exercise intolerance seems to be an adaptation exclusively in response to PE since data have demonstrated that treatment with $\beta$-blocker - carvedilol — did not alter exercise tolerance in $\alpha_{2 \mathrm{~A}} / \alpha_{2 \mathrm{Ca}} \mathrm{ARKO}$ mice ${ }^{102}$.

Such improvements in exercise tolerance after PE are probably associated with changes in the catabolic profile present in $\alpha_{2 \mathrm{~A}} / \alpha_{2 \mathrm{Ca}} \mathrm{ARKO}$, such as capillary rarefaction ${ }^{93,102}$. Recently, in the experiment of Bacurau et al. ${ }^{93}$, HF mice submitted to low-to-moderate aerobic exercise presented elevated exercise tolerance and motor performance, as well as attenuated soleus muscle mass atrophy in comparison with age-matched control $^{93}$. Authors also demonstrated that attenuated muscular atrophy could be associated with changes on regulating muscle mass pathways, since PE elevated the protein content of the anabolic arm (i.e., IGF-1, PI3K, phosphorylated AKT ${ }^{\text {Ser473, }}$ $\left.4 \mathrm{E}-\mathrm{BP} 1^{\mathrm{Thr} 37 / 46}, \mathrm{p} 70 \mathrm{~S} 6 \mathrm{~K}^{\mathrm{Thr} 389}\right)$ and decreased the catabolic arm (i.e., proteasome activity $)^{93}$.

Functional and structural parameters in $\alpha_{2 \mathrm{~A}} / \alpha_{2 \mathrm{C}}$ ARKO also seem to be responsive to $\mathrm{PE}^{109}$. In fact, experiments have demonstrated the effectiveness of PE to lead to decreased Ca2+ decay, concomitantly with the peak of $\mathrm{Ca} 2+$ transient increase in the cardiomyocytes of $\alpha_{2 \mathrm{~A}} / \alpha_{2 \mathrm{Ca}} \mathrm{ARKO}^{95}$. PE increases the balance between $\mathrm{Ca}^{2}+$ reuptake by SERCA2a and $\mathrm{Ca}^{2}+$ clearance by $\mathrm{NCX}^{92}$. These alterations on $\mathrm{Ca}^{2}+$ after $\mathrm{PE}$ are associated with improvement on cardiac function ${ }^{91,95}$.

Regarding molecular mechanisms, PE increases SERCA2a and SERCA2A/NCX ratio toward control group levels ${ }^{92,94}$. This phenomenon is an isolated product of increase on SERCA2a since NCX levels are found decreased in the heart of $\alpha_{2 \mathrm{~A}} / \alpha_{2 \mathrm{Ca}} \mathrm{ARKO}$ mice ${ }^{92,94}$. Furthermore, it is possible to observe an increase in

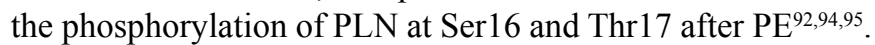

Therefore, considered together, these data indicate that PE leads to significant phosphorylation of PLN at Ser16 and Trh17 removing its inhibitory effect on SERCA2a, thus contributing to enhanced $\mathrm{Ca}^{2+}$ transient observed in trained animals ${ }^{95}$.

In turn, morphological alterations generally observed in remodeled hearts are impaired in trained $\alpha_{2 \mathrm{~A}} / \alpha_{2 \mathrm{C}} \mathrm{ARKO}$, since heart weight, cardiomyocyte width, LV mass, collagen content and cardiomyocyte CSA are decreased in these animals in comparison with sedentary age-matched control ${ }^{89,95}$. Considering these data it is possible to indicate that $\mathrm{PE}$ has an anti-remodeling effect on the heart of $\alpha_{2 \mathrm{~A}} / \alpha_{2 \mathrm{C}}$ ARKO mice ${ }^{89}$.

Moreover, some studies have aimed to describe the mechanisms associated with the anti-remodeling effect of PE. Experiments demonstrated that PE is capable of triggering significant decrease on the translocation to the nucleus of elements strongly associated with cardiac remodeling, such as calcineurin and its downstream targets - NFATe 3 and GATA-4 - in the heart of $\alpha_{2 \mathrm{~A}} / \alpha_{2 \mathrm{C}} \mathrm{ARKO}^{89}$. It is important mention that, in the heart of sedentary mice, both results were increased and associated with elevated $\beta$-MHC expression, suggesting a key role of this pathway in cardiac hypertrophy ${ }^{89}$. However, other factors indirectly associated with cardiac remodeling (i.e., RAS system) also demonstrated responsiveness to PE, since ANGII and ACE activity were decreased, while ACE2 expression was increased, after $\mathrm{PE}^{90}$.

Such post-PE improvements on cardiac $\mathrm{Ca}^{2+}$ handling, remodeling, and skeletal myopathy occur in conjunction with improving FS in $\alpha_{2 \mathrm{~A}} / \alpha_{2 \mathrm{C}} \mathrm{ARKO}$ to levels similar to those observed in control non-KO mice $89,91,95,102$. As in skeletal myopathy, data indicate that PE can also act as a preventive tool, since 3-month old animals without evident signals of HR — submitted to swimming exercise demonstrated preserved FS in comparison with sedentary mice ${ }^{92}$.

Table 3 shows a summary of the physiopathological elements present in $\alpha 2 \mathrm{~A} / \alpha 2 \mathrm{CaARKO}$, as well as the effects of PE. 
Table 3. Physiopathological characteristics observed in $\alpha 2 \mathrm{~A} / \alpha$ 2CaARKO mice and the effects of PE

\begin{tabular}{|c|c|}
\hline Physiopathological characteristics & Effects of PE \\
\hline \multicolumn{2}{|c|}{ Musculosqueletal functioning-Outcomes } \\
\hline$\uparrow$ Muscle atropy & $\downarrow$ \\
\hline$\downarrow$ Exercise tolerance & $\uparrow$ \\
\hline \multicolumn{2}{|c|}{ Cardiac calcium handling } \\
\hline$\downarrow$ SERCA2a & $\uparrow$ \\
\hline$\uparrow \mathrm{NCX}$ & $\downarrow$ \\
\hline$\downarrow$ SERCA2A/NCX ratio & $\uparrow$ \\
\hline$\downarrow$ Phosphorylation of PLN & $\uparrow$ \\
\hline \multicolumn{2}{|c|}{ Heart morphology and function } \\
\hline$\uparrow$ Heart weight & $\downarrow$ \\
\hline$\uparrow \mathrm{LV}$ mass & $\downarrow$ \\
\hline$\uparrow$ Cardiomyocyte CSA & $\downarrow$ \\
\hline$\uparrow$ Calcineurin & $\downarrow$ \\
\hline$\uparrow$ NFATe3 & $\downarrow$ \\
\hline$\uparrow$ GATA-4 & $\downarrow$ \\
\hline$\uparrow \beta$-MHC expression & $\downarrow$ \\
\hline$\uparrow \operatorname{RAS}$ & $\downarrow$ \\
\hline$\downarrow \mathrm{FS}$ & $\uparrow$ \\
\hline
\end{tabular}

CSA: Cross-sectional area; PE: Physical exercise; RAS: Renin-angiotensin system; EF: Ejection fraction; LV: Left ventricular; PE: Physical exercise; SERCA2: sarcoplasmic reticulum Ca2+-ATPase; $\mathrm{NCX:} \mathrm{Na}+\mathrm{Ca} 2+$ exchanger; PLN: Phospholamban; MHC: myosin heavy chain; FS: Fractional shortening

\section{Conclusions}

In conclusion, when the ethical principles of animal experimentation are considered, the use of animals in Physical Education as a field of knowledge has gained great prominence, particularly in understanding the pathophysiological mechanisms of CVD and the effects of PE on parameters that are unquantifiable in humans. Moreover, considering the data observed in this review, it is possible to infer that animal models of CVD seem to be an efficient and reliable tool to study the mechanisms responsible for the effects of PE on CVD.

\section{References}

1. WHO, World Health Organization. Global status report on noncommunicable diseases 2010. World Health Organization, 2011.

2. Fuster V, Bridget BK, editors. Promoting cardiovascular health in the developing world: a critical challenge to achieve global health. National Academies Press, 2010.

3. Pescatello LS, Franklin BA, Fagard R, Farquhar WB, Kelley GA, Ray CA. American College of Sports Medicine position stand.
Exercise and hypertension. Med Sci Sports Exerc, United States. 2004; 533-553.

4. Piepoli MF, Corrà U, Adamopoulos S, Benzer W, BjarnasonWehrens B, Cupples M, et al.. Secondary prevention in the clinical management of patients with cardiovascular diseases. Core components, standards and outcome measures for referral and delivery. Eur J Prev Cardiol. 2012.

5. SBC, Sociedade Brasileira de Cardiologia. Diretriz Sul-Americana de Prevenção e Reabilitação Cardiovascular. Arq Bras Cardiol, 2014; 103 (1).

6. Haskell WL, Lee IM, Pat RR, Powell KE, Blair SN, Franklin BA, et al. Physical activity and public health: updated recommendation for adults from the American College of Sports Medicine and the American Heart Association. Circulation. 2007; 116 (9).

7. Cornelissen VA, Neil AS. Exercise training for blood pressure: a systematic review and meta-analysis. J Am Heart Assoc. 2013; 2 (1).

8. Cornelissen VA, Fagard RH, Coeckelberghs E, Vanhees L.. Impact of resistance training on blood pressure and other cardiovascular risk factors a meta-analysis of randomized, controlled trials. Hypertension. 2011; 58 (5): 950-958.

9. Lawler PR, Filion KB, Eisenberg MJ. Efficacy of exercise-based cardiac rehabilitation post-myocardial infarction: a systematic review and meta-analysis of randomized controlled trials. Am Heart J. 2011; 162 (4): 571-584.

10. Ostman C, Jewiss D, Smart NA. The Effect of Exercise Training Intensity on Quality of Life in Heart Failure Patients: A Systematic Review and Meta-Analysis. Cardiology. 2016; 136 (2): 79-89.

11. Go AS; Mozaffarian D, Roger VL, Benjamin EJ, Berry JD, Borden WB et al. Heart disease and stroke statistics - 2013 update: a report from the American Heart Association. Circulation. 2013; 127: e6-e245.

12. World Health Organization. World health statistics, 2009.

13. Okamoto K, Kyuzo A. Development of a strain of spontaneously hypertensive rats. Japanese Jpn Circ J. 1963; 27 (3): 282-293.

14. Okamoto K, Kyuzo A. Participation of neural factor in the pathogenesis of hypertension in the spontaneously hypertensive rat. Jpn Circ J; 1967 8(2), 168-180.

15. Albrecht I. The hemodynamics in female spontaneously hypertensive rats (SHR). Jpn Circ J. 1974; 38 (8): 651-654.

16. Phillips MI, Mann JF, Haebara H, Hoffman WE, Dietz R, Schelling $\mathrm{P}$, et al. Lowering of hypertension by central saralasin in the absence of plasma renin. Nature. 1977; 270: 445-447.

17. Schlüter KD, Schreckenberg R, Rebelo RMC. Interaction between exercise and hypertension in spontaneously hypertensive rats: a meta-analysis of experimental studies. Hypertens Res. 2010; 33 (11): 1155-1161.

18. Evenwel RT, Kasbergen CM, Struyker Boudier HAJ. Central and regional hemodynamics and plasma volume distribution during the development of spontaneous hypertension in rats. Clin. Exp. Hypert. 1983.

19. Okamoto K, Tabei R, Fukushima M, Nosaka S, Yamori Y, Ichijima $\mathrm{K}$, et al. Further observations of the development of a strain of spontaneously hypertensive rats. Jpn Circ J. 1966; 30 (6): 703-716.

20. Weiss L, Lundgren Y, Folkow B. Effects of Prolonged Treatment with Adrenergic $\beta \square$ receptor Antagonists on Blood Pressure, 
Cardiovascular Design and Reactivity in Spontaneously Hypertensive Rats (SHR). Acta Physiol Scand. 1974; 91 (4): 447-457.

21. Adams AM, Bobik A, Korner PI. Differential development of vascular and cardiac hypertrophy in genetic hypertension. Relation to sympathetic function. Hypertension. 1989; 14 (2): 191-202.

22. Rizzoni D, Castellano M, Porten E, Bettoni G, Muiesan ML, Agabiti-Rosei E.. Vascular structural and functional alterations before and after the development of hypertension in SHR. Am J Hypertens. 1994; 7 (2): 193-

23. Smeda JS, RM Lee, Forrest JB. Structural and reactivity alterations of the renal vasculature of spontaneously hypertensive rats prior to and during established hypertension. Circ Res.1988; 63 (3): 518-533.

24. Wellens D, Borgers M, Verheyen A. Structural basis for resetting of baroreceptor regulation in spontaneously hypertensive rats (SHR). Experientia. 1973; 29 (10): 1268-1271.

25. Levy D. Prognostic implications of echocardiographically determined left ventricular mass in the Framingham Heart Study. N Engl J Med. 1990; 322 (22): 1561-1566.

26. Neto OB, Abade DT, Júnior MM, Mota GR, Orsatti FL, Silva $\mathrm{RCR}$, et al. Exercise training improves cardiovascular autonomic activity and attenuates renal damage in spontaneously hypertensive rats. J Sports Sci Med. 2013; 12: 52-59.

27. Jordão MT, Ladd FC, Coppi AA, Chopard RP, Michelini LC. Exercise training restores hypertension-induced changes in the elastic tissue of the thoracic aorta. J Vasc Res. 2011; 48 (6): 513-524.

28. Gündüz F, Koçer G, Ülker S, Meiselman HJ, Baskurt OK, Sentürk ÜK. Exercise training enhances flow-mediated dilation in spontaneously hypertensive rats. Physiol Res. 2011; 60 (4).

29. Silva DMR, Gomes-Filho A, Olivon VC, Santos TM, Becker LK, Santos RA, et al. Swimming training improves the vasodilator effect of angiotensin-(1-7) in the aorta of spontaneously hypertensive rat. J Appl Physiol. 2011; 111 (5): 1272-1277.

30. Guerrero J, Catros S, Derkaoui SM, Lalande C, Siadous R, Bareille R, et al. Cell interactions between human progenitorderived endothelial cells and human mesenchymal stem cells in a three-dimensional macroporous polysaccharide-based scaffold promote osteogenesis. Acta Biomaterialia 2013; 9 (9): 8200-8213.

31. Asano RY, Browne RAV, Sotero RDC, Sames MM, Moraes JFCND, Campbell, CSG, et al. Cycling above rather than below lactate threshold is more effective for nitric oxide release and post-exercise blood pressure reduction in individuals with type-2 diabetes. Motriz: J. Phys Ed. 2013; 19 (3): 633-640.

32. Bauer V, Ružena S. Nitric oxide-the endothelium-derived relaxing factor and its role in endothelial functions. Gen Physiol Biophys. 2010; 29 (4): 319-340.

33. Jia LL, Kang YM, Wang FX, Li HB, Zhang Y, Yu XJ, et al. Exercise training attenuates hypertension and cardiac hypertrophy by modulating neurotransmitters and cytokines in hypothalamic paraventricular nucleus. PloS one. 2014; 9 (1): e85481.

34. Ren CZ, Yang YH, Sun JC, Wu ZT, Zhang RW, Shen D, et al. Exercise Training Improves the Altered Renin-Angiotensin System in the Rostral Ventrolateral Medulla of Hypertensive Rats. Oxid Med Cell Longev. 2016.

35. Bertagnolli M, Campos C, Schenkel PC, de Oliveira VL, De Angelis K, Belló - Klein A, et al. Baroreflex sensitivity improvement is associated with decreased oxidative stress in trained spontaneously hypertensive rat. J Hypertens. 2006; 24 (12): 2437-43.

36. Kilic-Erkek O, Kilic-Toprak E, Caliskan S, Ekbic Y, Akbudak $\mathrm{IH}$, Kucukatay V, et al. Detraining reverses exercise-induced improvement in blood pressure associated with decrements of oxidative stress in various tissues in spontaneously hypertensive rats. Mol Cell Biochem. 2016; 412 (1): 209-219.

37. Brieger K, Schiavone S, Miller JR, Krause KH. Reactive oxygen species: from health to disease. Swiss Med Wkly. 2012; 142.

38. Csiszar A, Wang M, Lakatta EG, Ungvari Z. Inflammation and

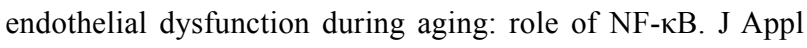
Physiol. 2008; 105 (4): 1333-1341.

39. El Assar M, Ângulo J, Rodríguez-Mañas L. Oxidative stress and vascular inflammation in aging. Free Radic Biol Med. 2013; 65: 380-401.

40. Herrera MD, Mingorance C, Rodríguez-Rodríguez R, de Sotomayor MA. Endothelial dysfunction and aging: an update. Ageing Res Rev. 2010; 9 (2): 142-152.

41. Van Der Loo B, Labugger R, Skepper JN, Bachschmid M, Kilo $\mathrm{J}$, Powell JM, et al. Enhanced peroxynitrite formation is associated with vascular aging. J Exp Med. 2000; 192 (12): 1731-1744.

42. Head GA., Adams MA. Time course of changes in baroreceptor reflex control of heart rate in conscious SHR and WKY: contribution of the cardiac vagus and sympathetic nerves. Clin Exp Pharmacol Physiol. 1988; 15 (4): 289-292.

43. Mulvany MJ, Nyborg N. An increased calcium sensitivity of mesenteric resistance vessels in young and adult spontaneously hypertensive rats. Br J Pharmamcol. 1980; 71 (2): 585-596.

44. Iriuchijma J. Sympathetic discharge rate in spontaneously hypertensive rats. Jap Heart J. 1973; 14: 350-356

45. Tesfamariam B, Halpern W. Endothelium-dependent and endothelium-independent vasodilation in resistance arteries from hypertensive rats. Hypertension. 1988; 11 (5): 440-444.

46. Head GA, Michael AA. Time course of changes in baroreceptor reflex control of heart rate in conscious SHR and WKY: contribution of the cardiac vagus and sympathetic nerves. Clin Exp Pharmacol Physiol. 1988; 15 (4): 289-292.

47. Masson G S, Costa TS, Yshii L, Fernandes DC, Soares PPS, Laurindo FR,et al. Time-dependent effects of training on cardiovascular control in spontaneously hypertensive rats: role for brain oxidative stress and inflammation and baroreflex sensitivity. PloS one. 2014; 9 (5): e94927.

48. Kishi, T, Hirooka Y, Katsuki M, Ogawa K, Shinohara K, Isegawa $\mathrm{K}$, et al. Exercise training causes sympathoinhibition through antioxidant effect in the rostral ventrolateral medulla of hypertensive rats. Clin Exp Hypertens. 2012; 34.4: 278-283.

49. Reja V, Goodchild AK, Pilowsky PM. Catecholamine-related gene expression correlates with blood pressures in SHR. Hypertension. 2002; 40 (3): 342-347.

50. Numao Y, Iriuchijima J. Effects of alpha and beta blockers on hemodynamics of SHR. Jap Heart J. 1974; 15 (2): 166-172.

51. Bohlen und Halbach OV. The renin-angiotensin system in the mammalian central nervous system. Curr Protein Pept Sci . 2005. 6 (4): 355-371.

52. Phillips MI, De Oliveira EM. Brain renin angiotensin in disease. J Mol Med. 2008; 86 (6): 715-722. 
53. Gyurko R, Donna W, Phillips MI. Antisense inhibition of AT1 receptor mRNA and angiotensinogen mRNA in the brain of spontaneously hypertensive rats reduces hypertension of neurogenic origin. Regul. Pept. 1993. 49 (2): 167-174.

54. Felix JVC, Michelini LC. Training-induced pressure fall in spontaneously hypertensive rats is associated with reduced angiotensinogen mRNA expression within the nucleus tractus solitarii. Hypertension. 2007. 50 (4): 780-785.

55. Touyz RM. Intracellular mechanisms involved in vascular remodelling of resistance arteries in hypertension: role of angiotensin II. Exp Physiol. 2005. 90 (4): 449-455.

56. Cardinale JP, Sriramula S, Mariappan N, Agarwal D, Francis J. Angiotensin II-Induced Hypertension Is Modulated by Nuclear Factor- $\kappa \mathrm{B}$ in the Paraventricular Nucleus. Hypertension. 2012. 59 (1): 113-121.

57. Coelho Junior HJ, Gambassi BB, Diniz TA, Fernandes IMDC, Caperuto ÉC, Uchida, MC, et al. Inflammatory Mechanisms Associated with Skeletal Muscle Sequelae after Stroke: Role of Physical Exercise. Mediators Inflamm 2016.

58. Masson GS, Borges JP, da Silva PPS, da Nóbrega ACL, Tibiriçá E, Lessa MA. Effect of continuous and interval aerobic exercise training on baroreflex sensitivity in heart failure. Auton Neurosci . 2016. 197: 9-13.

59. Rahmouni K, Davisson RL, Sigmund CD. Inflaming hypothalamic neurons raises blood pressure. Cell metab. 2011.14 (1): 3-4.

60. Takagishi M, Waki H, Bhuiyan ME, Gouraud SS, Kohsaka A, $\mathrm{Cui} \mathrm{H}$, et al. IL-6 microinjected in the nucleus tractus solitarii attenuates cardiac baroreceptor reflex function in rats. Am J Physiol Regul Integr Comp Physiol. 2010. 298 (1): 183-190.

61. Santos RAS, Campagnole-Santos MJ, Andrade SP. Angiotensin-(1-7): an update. Regul. Pept. 2000. 91 (1): 45-62.

62. Chobanian AV, Roccella EJ. The JNC 7 hypertension guidelines. Jama. 2003. 290 (10): 1312-1312.

63. Asano RY, Sales MM, Browne RAV, Nova JFV, Moraes HJCJ, Moraes MR, et al. Acute effects of physical exercise in type 2 diabetes: A review. World J Diabetes. 2014.

64. Barreto CB, Aguiar SDS, Palmeira R, Coelho Junior HJ, Gargaglione EML, Oliveira JF, et al. What is the Minimum Volume of Aerobic Physical Exercise Necessary to Elicit Postexercise Hypotension?. JEP Online. 2015. 18 (6).

65. Cornelissen VA, Buys R, Smart NA. Endurance exercise beneficially affects ambulatory blood pressure: a systematic review and meta-analysis. J Hypertens. 2013. 31 (4): 639-648.

66. Cornelissen VA, Smart NA. Exercise training for blood pressure: a systematic review and meta-analysis. J Am Heart Assoc. 2013. 2 (1): e004473.

67. Neves RVP, Souza MK, Passos CS, Bacurau RFP, Simoes HG, Prestes J, et al. Resistance Training in Spontaneously Hypertensive Rats with Severe Hypertension. Arq Bras Cardiol. 2016.106 (3): 201-209.

68. Moraes $\square$ Silva IC, De La Fuente RN, Mostarda C, Rosa K, Flues K, Damaceno $\square$ Rodrigues NR, et al. Baroreflex deficit blunts exercise training tations in hypertensive rats. Clin Exp Pharmacol Physiol 2010. 37 (3): 114-120.

69. Krieger EM, Brum PC, Negrão CE. Tate-of-the-Art Lecture Influence of Exercise Training on Neurogenic Control of Blood
Pressure in Spontaneously Hypertensive Rats. Hypertension. 1999. 34 (4): 720-723.

70. Brum PC, Da Silva GJJ, Moreira ED, Ida F, Negrao CE, Krieger EM. Exercise training increases baroreceptor gain sensitivity in normal and hypertensive rats. Hypertension. 2000. 36 (6), 1018-1022.

71. Xavier HT, Izar MC, Faria Neto JR, Assad MH, Rocha VZ, Sposito AC, et al. V Diretriz brasileira de dislipidemias e prevenção da aterosclerose. Arq Bras Cardiol. 2013. 101(4): 1-20.

72. Thygesen K, Alpert JS, Jaffe AS, Simoons ML, Chaitman BR, White HD. ESC/ACCF/AHA/WHF Task Force for the Universal Definition of Myocardial. Third universal definition of myocardial infarction. Eur Heart J. 2012. 33 (20): 2551-67.

73. Malfitano C; Loureiro TCA; Rodrigues B; Sirvente R; Salemi VMC; Rabechi NB, et al. Hyperglycaemia protects the heart after myocardial infarction: aspects of programmed cell survival and cell death. Eur J Heart Fail. 2010. 12: 659-667.

74. Rodrigues F; Feriani DJ; Barboza CA; Abssamra MEV; Rocha LY; Carrozi NM, et al. Cardioprotection afforded by exercise training prior to myocardial infarction is associated with autonomic function improvement. BMC Cardiovasc Disord, 2014. 14 (84).

75. Wu Y, Yin X, Wijaya C, Huang MH, McConnell BK. Acute myocardial infarction in rats. J Vis Exp, 2011. 16 (48).

76. Vona M, Codeluppi GM, Iannino T, Ferrari E, Bogousslavsky J, von Segesser LK. Effects of different types of exercise training followed by detraining on endothelium-dependent dilation in patients with recent myocardial infarction. Circulation. 2009. 119: 1601-8.

77. La Rovere MT, Bersano C, Gnemmi M, Specchia G, Schwartz,PJ. Exercise-induced increase in baroreflex sensitivity predicts improved prognosis after myocardial infarction. Circulation. 2002. 106 (8): 945-9.

78. Adamopoulos SJ, Parissis C, Kroupis M, Georgiadis D, Karatzas G; Karavolias K, et al. Physical training reduces peripheral markers of inflammation in patients with chronic heart failure. Eur Heart J. 2001. 22: 791-797.

79. Chen T, Cai M-X, Li Y-Y, He Z-X, Shi X-C, Song W, et al. Aerobic Exercise Inhibits Sympathetic Nerve Sprouting and Restores $\beta$-Adrenergic Receptor Balance in Rats with Myocardial Infarction. PLoS ONE. 2014. 9 (5).

80. Jorge L, Rodrigues B, Rosa KT, Malfitano C, Loureiro TCA, Medeiros A, et al. Cardiac and peripheral adjustments induced by early exercise training intervention were associated with autonomic improvement in infarcted rats: role in functional capacity and mortality. Eur Heart J. 2010 (32): 904-912.

81. Flores LJ, Figueroa DF, Sanches IC, Jorge L, Irigoyen MC, Rodrigues B, et al. Effects of exercise training on autonomic dysfunction management in an experimental model of menopause and myocardial infarction. Menopause. 2010. 17 (4): 712-717.

82. Rondon E, Brasileiro-Santos MS, Moreira ED, Rondon MU, Mattos KC, Coelho MA, et al. Exercise training improves aortic depressor nerve sensitivity in rats with ischemia-induced heart failure. Am J Physiol Heart CircPhysiol. 2006. 291:2801-2806.

83. Bozi LHM; Maldonado IRSC; Baldo MP; Silva MF; Moreira JBN; Novaes RD, et al. Exercise training prior to myocardial infarction attenuates cardiac deterioration and cardiomyocyte dysfunction in rats. Clinics (Sao Paulo). 2013. 68 (4): 549-556. 
84. Santos MHH; Higuchi ML; Tucci PJF; Garavelo SM; Reis MM; Antonio EL, et al. Previous exercise training increases levels of PPAR- $\alpha$ in long-term post-myocardial infarction in rats, which is correlated with better inflammatory response. Clinics (Sao Paulo). 2016. 71 (3): 163-168.

85. Barboza CA, Rocha LY, Mostarda CT, Figueroa D, Caperuto EC, De Angelis K, et al. Ventricular and autonomic benefits of exercise training persist after detraining in infracted rats. Eur J Appl Physiol. 2013.113: 1137-1146.

86. Remme WJ, Swedberg K. Task Force for the Diagnosis and Treatment of Chronic Heart Failure, European Society of Cardiology. Eur Heart J. 2001. 22 (17): 1527-60.

87. Triposkiadis F, Karayannis G, Giamouzi, G, Skoularigis J, Louridas G, Butler J, et al. The sympathetic nervous system in heart failure: physiology, pathophysiology, and clinical implications. J Am Coll Cardiol. 2009. 54 (19): 1747-1762.

88. Brum PC, Kosec J, Patterson A, Bernstein D, Kobilka B . Abnormal cardiac function associated with sympathetic nervous system hyperactivity in mice. American Am J Physiol Heart Circ Physiol. 2002. 283: 1838-1845.

89. Oliveira RSF, Ferreira JCB, Gomes ERM, Paixão NA, Rolin NPL, Medeiros A, et al. Cardiac anti-remodelling effect of aerobic training is associated with a reduction in the calcineurin/NFAT signalling pathway in heart failure mice. J Physiol. 2009. 587 (15): 3899-3910.

90. Pereira MG, Ferreira JCB, Bueno CRJR, Mattos KC, Rosa KT, Irigoyen $\mathrm{MC}$, et al. Exercise training reduces cardiac angiotensin II levels and prevents cardiacdys function in a genetic model of sympathetic hyperactivity-induced heart failure in mice. Eur $\mathbf{J}$ Appl Physiol. 2009. 105:843

91. Vanzelli AS, Medeiros A, Sirvente RS, Salemi VMC, Mady C. Brum, PC. Association of Physical Training with Beta-Blockers in Heart Failure in Mice. Arq Bras Cardiol. 2010.95 (3): 373-380

92. Medeiro A, Vanzelli AS, Rosa KT, Irigoyen MC, Brum PC. Effect of exercise training and carvedilol treatment on cardiac function and structure in mice with sympathetic hyperactivity-induced heart failure. Braz. J. Med. Biol. 2008. 41 (9): 812-817.

93. Bacurau AVN, Jannig PR, de Moraes WM, Cunha TF, Medeiros A, Barberi L, et al. Akt/mTOR pathway contributes to skeletal muscle anti-atrophic effect of aerobic exercise training in heart failure mice. Int J Cardiol. 2016. 214: 137-147.

94. Rolinn P, Medeiros A, Rosa KT, Mattos KC, Irigoyen MC, Krieger EM, et al. Exercise training improves the net balance of cardiac $\mathrm{Ca} 2$ handling protein expression in heart failure. Physiol Genomics. 2007. 29: 246 -252.

95. Vanzelli AS, Medeiros A, Rolim N, Bartholomeu JB, Cunha TF, Bechara LG, et al. Integrative effect of carvedilol and aerobic exercise training therapies on improving cardiac contractility and remodeling in heart failure mice. PLoS One. 2013. 8 (5).

96. Bacurau AV, Cunha TF, Souza RW, Voltarelli VA, Gabriel-Costa D, Brum PC. Aerobic Exercise and Pharmacological Therapies for Skeletal Myopathy in Heart Failure: Similarities and Differences. Oxid Med Cell Longev. 2016.

97. Brum PC, Bacurau AV, Cunha TF, Bechara LRG, Moreira JBN. Skeletal myopathy in heart failure: effects of aerobic exercise training. Exp physiol. 2014. 99 (4): 616-620.
98. Massie B, Conway M, Yonge R, Frostick S, Ledingham J, Sleight $\mathrm{P}$, et al. Skeletal muscle metabolism in patients with congestive heart failure: relation to clinical severity and blood flow. Circulation. 1987. 76 (5): 1009-1019.

99. De Sousa E, Veksler V, Bigard X, Mateo P, Ventura-Clapier R. Heart failure affects mitochondrial but not myofibrillar intrinsic properties of skeletal muscle. Circulation. 2000. 102 (15): 1847-1853.

100. Gielen S, Adams V, Möbius-Winkler S, Linke A, Erbs S, Yu J, et al. Anti-inflammatory effects of exercise training in the skeletal muscle of patients with chronic heart failure. J. Am. Coll. Cardiol. 2003. 42 (5): 861-868.

101. Cunha TF, Bacurau AV, Moreira JB, Paixão NA, Campos JC, Ferreira JC, et al. Exercise training prevents oxidative stress and ubiquitin-proteasome system overactivity and reverse skeletal muscle atrophy in heart failure. PloS one. 2012. 7 (8).

102. Medeiros A, Bacurau AVN, Vanzelli AS, Rolin NPL, Brum PC. Sistema nervoso simpático na insuficiência cardíaca: ênfase na sinalização adrenérgica cardíaca. Hipertensão. 2009. 12(3): 84-94

103. Fearnley CJ, Roderick HL, Bootman MD. Calcium signaling in cardiac myocytes. Cold Spring Harb Perspect Biol. 2011. 3 (11).

104. Marks AR. Calcium cycling proteins and heart failure: mechanisms and therapeutics. J Clin Invest. 2013. 123 (1): 46-52.

105. Luo M, Anderson ME. Mechanisms of altered $\mathrm{Ca} 2+$ handling in heart failure. Circ Res. 2013. 113 (6): 690-708.

106. Ai X, Curran JW, Shannon TR, Bers DM, Pogwizd SM. Ca2+/ calmodulin-dependent protein kinase modulates cardiac ryanodine receptor phosphorylation and sarcoplasmic reticulum $\mathrm{Ca} 2+$ leak in heart failure. Circ Res. 2005.97 (12): 1314-1322.

107. Piacentino V, Weber CR, Chen X, Weisser-Thomas J, Margulies KB, Bers DM, et al. Cellular basis of abnormal calcium transients of failing human ventricular myocytes. Circ Res. 2003.92 (6): 651-658.

108. Hilfiker-Kleiner D, Landmesser ULF, Drexler H. Molecular mechanisms in heart failure: focus on cardiac hypertrophy, inflammation, angiogenesis, and apoptosis. J. Am. Coll. Cardiol. 2006. 48 (9): 56-66.

109. Brum PC, Bacurau AVN, Medeiros A, Ferreira, JCB, Vanzelli AS, Negrão CE. Aerobic exercise training in heart failure: impacton sympathetic hyperactivity and cardiac and skeletal muscle function. Braz. J. Med. Biol. 2011

110. Kessler EL, Boulaksil M, van Rijen HVM, Vos MA, Van Veen TAB. Front Physiol. 2015. 5 (482).

111. Segura AM, Frazier OH, Buja LM. Fibrosis and heart failure. Heart Fail Rev. 2014. 19 (2): 173-185.

112. Tsutsui H, Kinugawa S, Matsushima S. Oxidative stress and heart failure. Am J Physiol Heart Circ. 2011.301 (6): 2181-2190.

113. Van Empel VPM, Bertrand AT, Hofstra L, Crijns HJ, Doevendans PA, De Windt LJ. Myocyte apoptosis in heart failure. Cardiovasc Res. 2005.67 (1): 21-29.

114. Kim NH, Kang PM. Apoptosis in cardiovascular diseases: mechanism and clinical implications. Korean Circ J. 2010.40 (7): 299-305.

115. Medeiros A, Rolim NP, Oliveira RS, Rosa KT, Mattos KC, Casarini $\mathrm{DE}$, et al. Exercise training delays cardiac dysfunction and prevents calcium handling abnormalities in sympathetic hyperactivity-induced heart failure mice. J Appl Physiol (1985). 2008. 104 (1): 103-109.

116. Grans CF, Feriani DJ, Abssamra MEV, Rocha LY, Carrozzi NM, Mostarda $\mathrm{C}$, et al. Resistance training after myocardial infarction 
in rats: Its role on cardiac and autonomic function. Arq. Bras. Cardiol. 2014. 103 (1): 60-68.

117. Biancardi VC, Son SJ, Ahmadi S, Filosa JA, Stern JE. Circulating Angiotensin II Gains Access to the Hypothalamus and Brain Stem During Hypertension via Breakdown of the Blood-Brain Barrier. Hypertension. 2014. 63: 572-579.

118. Biancardi VC, Stern JE. Compromised blood-brain barrier permeability: novel mechanism by which circulating angiotensin II signals to sympathoexcitatory centres during hypertension. J. Physiol. 2016. 594: 1591-1600

\section{Acknowledgments}

Bruno Rodrigues, Kátia De Angelis, and Maria-Cláudia Irigoyen received financial support from Conselho Nacional de Pesquisa e Desenvolvimento (CNPq-BPQ).

\section{Corresponding author}

Bruno Rodrigues, Ph.D.

Faculty of Physical Education, University of Campinas (UNICAMP), Adapted Physical Activity. Av. Érico Veríssimo, 701 Cidade Universitária "Zeferino Vaz" Barão Geraldo Campinas, São Paulo, Brazil Email: prof.brodrigues@gmail.com

Manuscripted received on November 28, 2016

Manuscripted accepted on December 02, 2016

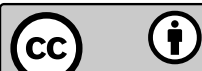

Motriz. The Journal of Physical Education. UNESP. Rio Claro, SP, Brazil - eISSN: 1980-6574 - under a license Creative Commons - Version 3.0 